\title{
NOVENA MESA REDONDA
}

Doctor Arias: - Yo me voy a referir al problema del tétano, creo que en el futuro se debe tratar de una manera conservadora, no soy partidario de la histerectomía.

Doctor Domínguez: En nuestro país tenemos dos estadísticas diferentes de dos grupos de años; hasta el 55 el porcentaje mayor de histerectomías de causa obstétrica eran de subtotales. Ahora tenemos el porcentaje de histerectomías totales casi de un $90 \%$. Personalmente me inclino hacia la histerectomía total, y me atrevo a decir esto por hallarme ante un auditorio de especialistas. La histerectomía total tiene muchos más riesgos que la subtotal, tiene que ser ejecutada por cirujanos expertos. No la aconsejamos indiscriminadamente; pero hay casos en que se impone, especialmente en casos en que por acretismo placentario bajo hemos hecho subtotal, luego nos vimos obligados a totalizar la histerectomía.

En los casos de afibrinogenemia, aun con el riesgo que significa la operación, la recomendamos, porque el segmento del cuello que está sangrando va a persistir haciéndolo aun después de la histerectomía parcial.

Por supuesto en las dos indicaciones que mencionó el doctor Avilés: ruptu- ra del segmento, en los grandes desgarros del cuello, aún si en el estado postpartum y post-cesárea inmediato la dilatación del cuello y su blandura no nos permitan diferenciarlo bien de la vagina, pero eso sí repito que la histerectomía total no debe ser practicada sino por obstetras y ginecólogos capacitados para ello.

Sobre tétanos tenemos poca experiencia; en los quince años de graduados tuvimos un caso de tétanos con embarazo de tres meses, lo tratamos conservadoramente, salvamos a la madre y al hijo. Sólo vimos un caso de tétanos del post-partum. No era de nosotros, que evolucionó fatalmente. De todos modos creo que en estos casos de tétanos se debe ser conservador.

Respecto de la histerectomía, depende de muchos factores. Nosotros hacemos la histerectomía subtotal, debido a que una subtotal es mucho menos traumatizante, más corta y menos peligrosa. El ideal es poder hacer la total, en las otras indicaciones, que en realidad no es tan difícil como se piensa.

Al doctor Avilés: - No ha obtenido casos de afibrinogenemia en sus operaciones, y si los han tenido, ¿cómo los han tratado? 
Doctor Avilés: -En mi disertación hablé de dos casos que tenían afibrinogenemia y que fueron sometidos a una histerectomía. El número de casos controlados es deficiente porque en los medios de laboratorio no se cuenta normalmente con ella. La histerectomía en estos casos debe ser oportuna. No se puede esperar hasta el último momento porque viene un colapso y la enferma muere. El uso indiscriminado de fibrinógeno para combatir estos cuadros es perfectamente inútil si acaso en un momento dado no reaccionan. $\mathrm{Si}$ se ve que la enferma no reacciona ni con las transfusiones ni con los fibrinógenos, debe de procederse sin pérdida de tiempo a la histerectomía.

Al doctor Martínez: - ¿Cuál es el momento más propicio para hacer la indicación de la histerectomía en el shock bacteriológico?

Doctor Martínez: -Depende precisamente del diagnóstico bueno que se haga. No hay que confundir el shock bacteriológico con el aborto séptico, ni con necrosis, colitis aguda, colitis hemorrágica aguda, necrosis hepática aguda, etc. El tiempo ideal para nosotros está representado precisamente por esos momentos en que surge el colapso, ya que la experiencia nos ha demostrado que en las lesiones renales la recuperación de la paciente en materia de insuficiencia renal ha sido mucho más rápida cuando más rápido se ha intervenido. Nunca intervenimos en condiciones de shock. Si se opera en shock, creo que se va a obtener una muerte más. La intervención está supeditada a la recuperación de la paciente del estado de shock.
Marzo-Abril 1963
Rev. Col. Obs. y Ginec

Al doctor Martínez: - ¿Qué opina del tratamiento médico para cambiar el tratamiento radical en dicho shock, y qué espera de él?

Doctor Martínez: - Hemos traído hoy unas ideas un poco radicales. Puede que dentro de 4 años vengamos a decir que estábamos cometiendo una barbaridad. Hemos optado por la histerectomía rutinaria porque cuando fuimos conservadores no obtuvimos sino dos muertes. Quizá con el progreso de las drogas nosotros podamos volver a ser conservadores a este respecto.

Al doctor Cobo: - iUsa sistemáticamente derivados de la Rauwolfia en los tratamientos de la preclampsia, y con qué criterio?

Doctor Cobo: - En el tratamiento clínico general de todas nuestras pacientes toxémicas, se usa en términos generales, sin que sea usado sistemáticamente. El criterio que nos lleva a usar la rauwolfia es reforzar la acción de los demás sedantes y obtener hipotensión moderada lenta tardía. En el trabajo que presenté se usó en todos para hacer comparables los resultados. A este respecto quiero agregar algo que omití en la presentación: La depresión obtenida en la histerocontractilidad no es específica o definida; es algo que resulta de todos estos medicamentos. La etapa posterior será la de obtener el descarte, por medio de series según las cuales no se administren sino uno sólo de estos medicamentos. Así encontraremos cuál es el agente responsable de la depresión. Personalmente pienso que sea el reposo.

Al doctor Cobo: - ¿Qué experiencia tienen sobre la acción de los derivados 
de la promazina, Largactil y Plegisil, sobre la contracción uterina y su uso en tratamientos de preclampsia?

Doctor Cobo: -Este problema ha sido bastante bien tratado por Caldeyro y Barcia. Ellos encontraron en pacientes toxémicas lo que clásicamente se ve: disminución de la tensión arterial cuando se aplica intravenosamente. Sin embargo, esto lo han reportado en repetidas ocasiones, el Largactil no posee ningún efecto depresor sobre la contractilidad uterina, usado aisladamente, ya sea normal o patológica.

$\mathrm{Al}$ doctor Cobo: - ¿Efectos del sulfato de magnesia sobre el tono?

Doctor Cobo: -Ninguno. Las descripciones hechas por ellos lo demuestran. En algunos casos, usando dosis altas se observó una ligera depresión, pero inmediatamente se suspendió la dosis cesó también la depresión; fue algo muy leve.

Al doctor Avilés: - ¿En qué casos de Abruptio placentae hace histerectomía?

Doctor Avilés:-El tratamiento por excelencia en la hora actual es el conservador. Si este caso así no se resuelve, entonces sería el momento de llegar a una histerectomía. Por otra parte, si con el tratamiento conservador de la abruptio placentae, la enferma sigue sangrando una vez evacuado el útero, también tendríamos que llegar a la histerectomía en razón de que el órgano estaría ya profundamente alterado y no sería capaz de contraerse para suprimir la hemorragia.

Doctor Arias: -Estamos de acuerdo con el doctor Avilés, en los casos de histerectomía que se tenga que hacer, por Abruptio placentae. Nosotros damos fibrinógeno a ver si logramos interrumpir la hemorragia. Si tenemos que hacer histerectomía la hacemos subtotal, por ser más rápida, y la complementamos seis semanas después con una conización del cuello.

Doctor Avilés: -Bueno, el doctor Arias tiene razón al hablar del fibrinógeno, lo que sucede es que una histerectomía en el momento oportuno puede ser más operante, pero ambas cosas se pueden usar simultáneamente.

Nosotros tenemos el concepto de que si no mejoramos la discrasia hemorrágica, no podemos intervenir. En nuestro medio aplicamos la tabla de Roussel. Solamente somos intervencionistas en materia de Abruptio placentae, cuando después de esperar este tiempo lúcido que da la tabla, queremos obtener un producto de la concepción vivo. Los que operan o no, tienen la misma mortalidad materna. Nosotros tan solo operamos para mejorar un poco la mortalidad infantil; hasta ahora no hemos tenido nunca necesidad de hacer una histerectomía; porque si no se mejoran las condiciones de coagulabilidad sanguínea, prácticamente la histerectomía no tiene ningún objeto, sería prácticamente destruír a la mujer. Nosotros creemos que la histerectomía no se debe hacer. Más bien mejorar la diáfisis hemorrágica, recuperar el fibrinógeno, hacer transfusiones, combatir la fibrinolisina y sobre todo sacar la placenta, porque mientras la placenta no se saque, el cuadro de fibrinogenemia continúa. 
- ¿Qué porcentajes de histerectomías tienen los servicios a los que pertenecen los miembros de la Mesa entre el total de rupturas uterinas?

Doctor Domínguez: - Nosotros no podemos decir el porcentaje exacto que tenemos de histerectomías. En la última década nuestro servicio de maternidad Concepción Palacios está haciendo un porcentaje mucho mayor de histerorrafias que de histerectomías. Ya les dije antes más o menos que el porcentaje era de 1955 hasta ahora, del $90 \%$ subtotales. Nuestra tendencia es un conservatismo racional. Naturalmente que depende de las circunstancias de la ruptura y demás factores que influyan a agravarla o atenuarla, pero en general nosotros optamos por histerorrafia.

Doctor Avilés: -Coincido con el doctor Domínguez en que el número de histerectomías en ruptura uterina ha descendido notablemente, aunque es imposible dar porcentajes sin haber venido especialmente preparados para ello. En los cuadros que traje figura que el número de histerectomías ha disminuído en un $50 \%$ en circunstancias en que el número de rupturas ha aumentado.

Doctor Arias: - Estoy de acuerdo con mis colegas. En nuestro servicio somos más radicales y por eso tenemos menos casos de rupturas uterinas, pero sí quiero dejar la constancia de que la histerectomía se practica con menos frecuencia y preferimos la sutura simple del útero.

Doctor Martinez: -Creo que la ruptura uterina ha ascendido debido a que una droga muy buena, el Pitocín, cayó en malas manos. Nosotros tenemos, de cuatro histerectomías practicadas, tres causadas por Pitocín. La ruptura provocada por esta droga no es la misma que la provacada por deficiencias en una cesárea; en esos casos, que generalmente vienen de la calle, hemos encontrado rupturas que van a veces hasta la vejiga, ante los cuales sólo se puede hacer la histerectomía.

Doctor Cobo: -Entre nosotros, dado que no se hacen la histerorrafia y ligadura de trompas, no se resisten este tipo de intervenciones. Además, las pacientes que nos consultan son de las clases menos dotadas, de manera que reservamos la histerorrafia para aquellos casos en que podamos tener la certeza de un control prenatal sobre embarazos posteriores. Por eso creo que tenemos más histerectomías que histerorrafias en nuestro medio, aunque no sé los números exactos.

Al doctor Avilés: — ¿En la histerectomía suturan la vagina, o la dejan abierta?

Doctor Avilés: —En general afronto la vagina con tres o cuatro puntos. Hay ocasiones en que la vagina, sobre todo si se utiliza para hacer un drenaje vaginal, de los cuales el número es muy reducido, queda prácticamente entreabierta. Cuando el caso es de orden infeccioso, pienso que es casi más conveniente el dejar permeable la vagina. Cuando el caso es de orden traumático y sobre todo hemorrágico, vale más la pena suturar la vagina. 
Doctor Domínguez: - Nosotros ha- cros a los ángulos vaginales para precemos prácticamente lo mismo; hasta venir el posible descenso de la pared hace pocos años dejábamos un peque- vaginal.

ño drenaje vaginal que hemos suprimi- Doctor Avilés: Olvidé dar ese detado, pero siempre hacemos la suspensión lle y que es muy interesante y justifica de la vagina, mediante la sutura de los plenamente lo que acaba de decir el ligamentos redondos y de los útero-sa- doctor Domínguez. 